\title{
Comprehensive automation of the solid phase extraction gas chromatographic mass spectrometric analysis (SPE-GC/MS) of opioids, cocaine, and metabolites from serum and other matrices
}

\author{
Oliver Lerch • Oliver Temme • Thomas Daldrup
}

Received: 19 December 2013 / Revised: 28 February 2014 / Accepted: 3 April 2014 / Published online: 2 May 2014

(C) The Author(s) 2014. This article is published with open access at Springerlink.com

\begin{abstract}
The analysis of opioids, cocaine, and metabolites from blood serum is a routine task in forensic laboratories. Commonly, the employed methods include many manual or partly automated steps like protein precipitation, dilution, solid phase extraction, evaporation, and derivatization preceding a gas chromatography (GC)/mass spectrometry (MS) or liquid chromatography (LC)/MS analysis. In this study, a comprehensively automated method was developed from a validated, partly automated routine method. This was possible by replicating method parameters on the automated system. Only marginal optimization of parameters was necessary. The automation relying on an $\mathrm{x}-\mathrm{y}-\mathrm{z}$ robot after manual protein precipitation includes the solid phase extraction, evaporation of the eluate, derivatization (silylation with $\mathrm{N}$-methyl- $\mathrm{N}$ trimethylsilyltrifluoroacetamide, MSTFA), and injection into a GC/MS. A quantitative analysis of almost 170 authentic serum samples and more than 50 authentic samples of other matrices like urine, different tissues, and heart blood on cocaine, benzoylecgonine, methadone, morphine, codeine, 6monoacetylmorphine, dihydrocodeine, and 7 aminoflunitrazepam was conducted with both methods proving that the analytical results are equivalent even near the limits of quantification (low $\mathrm{ng} / \mathrm{ml}$ range). To our best knowledge, this application is the first one reported in the literature employing this sample preparation system.
\end{abstract}

\footnotetext{
O. Lerch $(\bowtie)$

GERSTEL GmbH \& Co. KG, Eberhard-Gerstel-Platz 1,

45473 Muelheim, Germany

e-mail: oliver_lerch@gerstel.de

O. Temme $\cdot$ T. Daldrup

Department of Forensic Toxicology, Institute of Legal Medicine,

University Hospital Duesseldorf, Moorenstrasse 5,

40225 Duesseldorf, Germany
}

Keywords Opiates $\cdot$ Opioids $\cdot$ Cocaine $\cdot$ Solid phase extraction $(\mathrm{SPE}) \cdot$ Automation $\cdot \mathrm{GC} / \mathrm{MS}$

\section{Introduction}

Analysis of drugs and metabolites in biological fluids or tissues usually requires sample preparation for cleanup and enrichment. In recent years, in conjunction with very sensitive and selective mass spectrometers, protein precipitation alone [1] or "dilute and shoot" methods [2, 3] were also used whereat these methods may suffer from sample-dependent matrix effects able to compromise the accuracy of the results. Although the number of LC-MS/MS methods is rapidly increasing [4-7], gas chromatography (GC)-mass spectrometry (MS)/(MS) is still the standard routine analysis instrument in many forensic laboratories [4, 8-10].

A variety of sample preparation techniques like liquidliquid extraction (LLE) [11], supported liquid extraction (SLE) [12-15], static headspace extraction (HS), and solid phase micro extraction (SPME) [16] is used.

Solid phase extraction (SPE) is one of the most popular extraction techniques for toxicological analyses of biological fluids and tissues [4, 12, 17]. Usually, polypropylene cartridges with a fixed sorbent bed (e.g., mixed mode cation exchange cartridges) are applied.

Numerous systems for automating SPE are commercially available [18]. In many forensic laboratories, benchtop systems like the ASPEC from Gilson [5, 6, 19] or the RapidTrace from Biotage [20-22] which employ standard SPE cartridges and mimic the manual workflow are used. Complete automation of sample preparation and analysis is possible with online SPE systems where the SPE cartridge is integrated into an LC flow path. Systems with nonautomatically exchangeable [23, 24] and automatically exchangeable [25-27] cartridges are 
available. Online coupling of SPE to GC is less common and more complex [12] but an important step to reduce manual work and handling errors.

Numerous methods for the analysis of opioids, cocaine, and metabolites in different matrices were published. The compounds were analyzed from different matrices like urine $[9,28,29]$, whole blood, serum, plasma [5, 9, 7], saliva [6], hair [8], or post-mortem samples [17]. In this study, a completely automated SPE-GC/MS method was developed from a validated, partly automated (SPE) analysis method. Automation is performed by different modules attached to an $\mathrm{x}-\mathrm{y}-\mathrm{z}$ robot. This allows mimicking the manual workflow of sample dilution, SPE, evaporation, derivatization, and sample injection. Almost 170 authentic serum samples and more than 50 authentic samples of other matrices were analyzed in parallel with both methods. Equivalence of results therefore, the validity of the method and the suitability of the automated system for routine forensic analysis, should be proven by this study design.

\section{Materials and methods}

Solvents, reagents, standards, and materials

All analytes and deuterated analogs were certified standards. 7-Aminoflunitrazepam $(1 \mathrm{mg} / \mathrm{ml}$ in acetonitrile $)$ and dihydrocodeine ( $1 \mathrm{mg} / \mathrm{ml}$ in methanol) were purchased from Lipomed (Arlesheim, Switzerland). 7-Aminoflunitrazepam$\mathrm{d}_{7}$, 6-monoacetylmorphine, 6-monoacetylmorphine- $\mathrm{d}_{3}$ (each $0.1 \mathrm{mg} / \mathrm{ml}$ in acetonitrile), methadone, morphine, morphine$\mathrm{d}_{3}$, codeine, codeine- $\mathrm{d}_{3}$, dihydrocodeine- $\mathrm{d}_{6}$ (each $0.1 \mathrm{mg} / \mathrm{ml}$ in methanol), methadone- $d_{9}$, benzoylecgonine, benzoylecgonine- $\mathrm{d}_{3}$ (each $1 \mathrm{mg} / \mathrm{ml}$ in methanol), cocaine, and cocaine- $\mathrm{d}_{3}$ (each $1 \mathrm{mg} / \mathrm{ml}$ in acetonitrile) were purchased from LGC Promochem (Wesel, Germany). For calibration and solvent quality controls, multi-compound solutions and one multi-compound internal standard solution containing deuterated analogs of every analyte were prepared in methanol. Each $20 \mu \mathrm{l}$ of the internal standard solution was added to samples, calibration samples, and quality controls. Blood, urine, and tissue samples were taken from authentic forensic cases of the Institute of Legal Medicine (Duesseldorf, Germany). Internal controls consisting of drug-negative serum (given by the Center of Haemostaseology, University Hospital Duesseldorf, Germany) and the above-mentioned standards were prepared by the Institute of Legal Medicine. The external controls were certified testing materials (lyophilized serum "Medidrug BTMF 2 S-plus" purchased from Medichem, Steinenbronn, Germany).

All solvents and salts were of analytical grade and purchased from VWR (Darmstadt, Germany). $N$-Methyl- $N$ trimethylsilyltrifluoroacetamide (MSTFA) for silylation was from Macherey-Nagel (Dueren, Germany) for the partly automated method and from Sigma-Aldrich (Taufkirchen, Germany) for the automated method. Bond Elut Certify $130 \mathrm{mg}, 3 \mathrm{ml}$ format SPE cartridges from Agilent Technologies (Waldbronn, Germany) were used. For automated solid phase extraction, these cartridges were cut at the top, equipped with a transport adapter and a disposable cannula (Fig. 1). Cartridges in such format are commercially available from other vendors like Macherey \& Nagel, Sigma-Aldrich, Phenomenex, and Bekolut.

For solid phase extraction, $0.15 \mathrm{M}$ acetic acid, a phosphate buffer of pH 7.9 (4.49 g Na $\mathrm{HPO}_{4}+0.2 \mathrm{~g} \mathrm{KH}_{2} \mathrm{PO}_{4}$ ad $400 \mathrm{ml}$ $\mathrm{H}_{2} \mathrm{O}$ ), and a mixture of dichloromethane/isopropanol/25\% ammonia solution 40/10/1 $(v / v / v)$ for analyte elution were prepared. A mixture of isooctane/MSTFA 19/1 $(v / v)$ was used for manual derivatization and a mixture of isooctane/pyridine/ MSTFA 14/5/1 $(v / v / v)$ for automated derivatization.

Inlet liners and injection vials were deactivated using a solution of $5 \%$ dichlorodimethylsilane in toluene.

\section{Instrumentation}

Measurements with the partly automated, validated analysis method were conducted on a $7890 \mathrm{GC} / 5975$ mass selective detector (MSD) equipped with an HP-5MS column $30 \mathrm{~m}, d_{\mathrm{i}}$ $0.25 \mathrm{~mm}$, and $\mathrm{d}_{\mathrm{f}} 0.25 \mu \mathrm{m}$. A 7683B autosampler was used for injection into a hot split/splitless inlet (all Agilent Technologies). For solid phase extraction, a RapidTrace SPE Workstation (Biotage, Uppsala, Sweden) and for evaporation of the eluates a heating block (Medax, Neumuenster, Germany) with ten nitrogen-streamed vial positions (Gebr. Liebisch, Bielefeld, Germany) were used.

Comprehensive automation of sample preparation-performed in a different laboratory-was based on a MultiPurpose Sampler (MPS) (Fig. 2, GERSTEL, Muelheim, Germany) which is a flexible platform with numerous modules available (e.g., for centrifugation and filtration) so that different sample preparation methods can be automated. It carried two syringes, one $2.5 \mathrm{ml}$ for sample preparation steps and one $10 \mu \mathrm{l}$ for sample injection into a

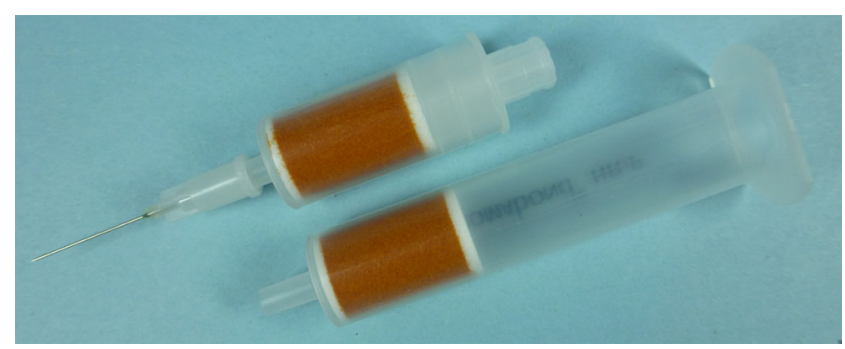

Fig. 1 Solid phase extraction (SPE) cartridges. Top: Solid phase extraction cartridge equipped for automated SPE. Bottom: Standard solid phase extraction cartridge 
Fig. 2 System for automated dilution, solid phase extraction, eluate evaporation, derivatization, injection, and GC/MS analysis. $\mathrm{X}-\mathrm{y}-\mathrm{z}$ dual head robotic autosampler with following modules (from right to left): evaporation station, $2 \times$ solvent filling station, SPE module, tray for sample vials, tray for SPE cartridges, tray for empty eluate vials, wash station, and agitator

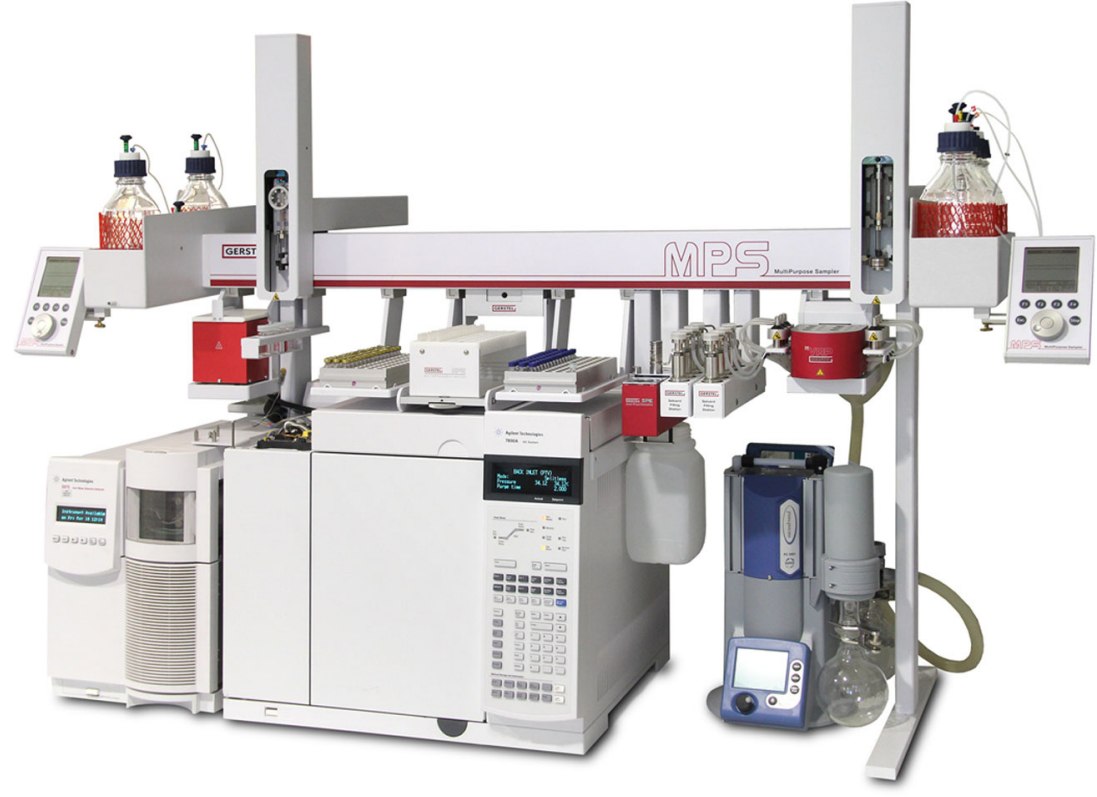

Programmed Temperature Vaporization (PTV) inlet (Cooled Injection System CIS 4, GERSTEL) coupled to a $6890 \mathrm{GC} /$ 5975 MSD (Agilent Technologies). Separation was done on an Rxi-5Sil MS column $30 \mathrm{~m}, \mathrm{~d}_{\mathrm{i}} 0.25 \mathrm{~mm}$, and $\mathrm{d}_{\mathrm{f}} 0.25 \mu \mathrm{m}$ from Restek (Bad Homburg, Germany) having very similar retention characteristics as the HP-5MS. Additionally, the autosampler was equipped with a module for SPE, one for evaporation of solvents under controlled vacuum and temperature (multi-position eVAPoration station, mVAP), one for shaking under controlled temperature (Agitator), and one for supplying large volumes of solvents (Solvent Filling Station 2, SFS 2, all GERSTEL). All solvents and samples were delivered by the $2.5-\mathrm{ml}$ syringe which included a gas supply for drying of SPE cartridges.

The RapidTrace SPE Workstation was controlled via RapidTrace SPE Workstation software (Biotage). All MPS sample preparation steps were flexibly combined in and controlled by Maestro software (GERSTEL). The sequential sample preparation steps were automatically overlapped with chromatographic runs and other waiting times so that the $\mathrm{GC} /$ MS-system is effectively used. A scheduler window gives a graphical overview over the complete sequence and shows what step is currently executed. ChemStation software (Agilent Technologies) was used to control the GC/MS system and to evaluate the recorded chromatograms.

Analysis methods

\section{Common steps of sample preparation}

All liquid samples (urine, blood, serum) and serum controls were handled in the same way: proteins were precipitated by dropwise addition of a mixture of $0.6 \mathrm{ml}$ sample, $0.1 \mathrm{ml}$ water, and $20 \mu \mathrm{l}$ internal standard solution to a mixture of $1 \mathrm{ml}$ acetonitrile and $0.1 \mathrm{ml}$ isopropanol. After mixing and centrifugation (RCF $17,530 \times g$ ), an aliquot of $0.75 \mathrm{ml}$ of the supernatant was taken for the partly automated analysis method. Another aliquot of $0.75 \mathrm{ml}$ was collected and stored in the freezer at $-20^{\circ} \mathrm{C}$ for later analysis with the automated system. The storage period for the supernatants ranged from some days to several months.

Tissues (brain and kidney, native and lyophilized) were homogenized with an Ultra Turrax. An aliquot of approximately $0.6 \mathrm{~g}$ was weighed and handled like the liquids above, whereas the acetonitrile/isopropanol solution was given to the sample mixture for protein precipitation. The exact weight was noted for calculation of analyte concentrations.

\section{Sample preparation: partly automated, validated routine method}

A $0.75-\mathrm{ml}$ aliquot of the supernatant of the protein precipitation was diluted with $4.25 \mathrm{ml}$ of phosphate buffer, and the SPE cartridge was conditioned with $2 \mathrm{ml}$ methanol and $2 \mathrm{ml}$ phosphate buffer. After addition of the diluted sample, the cartridge was washed with $2 \mathrm{ml}$ water, $2 \mathrm{ml}$ acetic acid $(0.15 \mathrm{M})$, and $2 \mathrm{ml}$ methanol, shortly dried with nitrogen, and eluted with $2 \mathrm{ml}$ of the mentioned elution solvent.

The eluate was evaporated to dryness in a stream of nitrogen at $60{ }^{\circ} \mathrm{C}$ and reconstituted in $0.2 \mathrm{ml}$ of the derivatization solution. After shaking and incubating for $30 \mathrm{~min}$ at $90{ }^{\circ} \mathrm{C}$, an aliquot of $2 \mu \mathrm{l}$ was injected into the $\mathrm{GC} / \mathrm{MS}$ via a hot inlet at $270{ }^{\circ} \mathrm{C}$. 


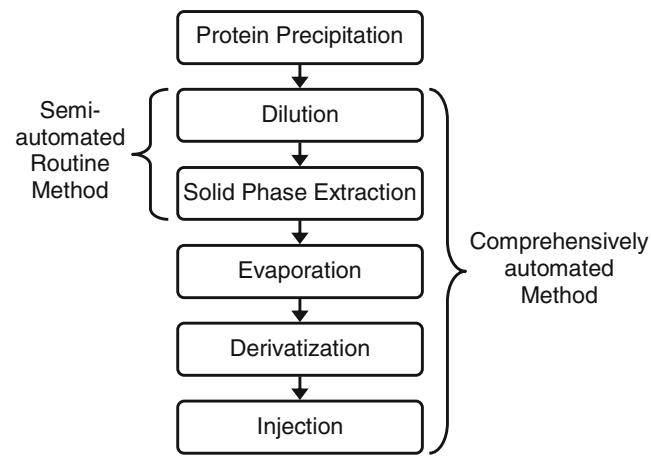

Fig. 3 Scheme of the sample preparation workflow indicating automated parts of both methods

\section{Sample preparation: completely automated method}

The completely automated method was performed analogously to the partly automated method (Fig. 3) described before with some adaptations: Since no adequate vial for taking up the diluted sample $(5 \mathrm{ml})$ was available, a part of the dilution was done in the autosampler syringe before injection into the SPE cartridge. For this, the original sample (supernatant of the protein precipitation) was diluted $1: 1$ with $0.75 \mathrm{ml}$ of phosphate buffer. Half of this diluted sample $(0.75 \mathrm{ml})$ was aspirated into the syringe followed by $1.75 \mathrm{ml}$ phosphate buffer resulting in the same dilution as in the partly automated method. The syringe content was injected into the SPE cartridge, and the procedure was repeated to transfer the entire sample.

Furthermore, the elution volume was adapted to speed up evaporation and since the preferred elution vial $(2 \mathrm{ml}$ format is cheaper than $4 \mathrm{ml}$ format) could not be filled too high for later automated evaporation in the mVAP station. Therefore, an elution profile of the analytes from the SPE cartridge was recorded by fractionated elutions with portions of solvent determining the main analytes containing fractions. The evaporation of the eluate was done in the mVAP station at $70{ }^{\circ} \mathrm{C}$, $300 \mathrm{rpm}$ shaking, and a pump vacuum of $8 \mathrm{kPa}$. Evaporation time was optimized and finally set to a value of 6 min for reliable evaporation to dryness. In order to speed up the method, the derivatization procedure was modified to the described solvent composition (see "Solvents, reagents, standards, and materials" section) and a reaction time of $5 \mathrm{~min}$.

An aliquot of $2 \mu \mathrm{l}$ of the derivatized eluate was injected into the CIS 4 (PTV inlet) at $50{ }^{\circ} \mathrm{C}$. The inlet was heated with $12{ }^{\circ} \mathrm{C} / \mathrm{s}$ to $280{ }^{\circ} \mathrm{C}$ held for $5 \mathrm{~min}$.

\section{Analysis parameters for GC/MS}

Separation was performed on the named columns with constant helium flow of $1 \mathrm{ml} / \mathrm{min}$ and the following temperature program: $140{ }^{\circ} \mathrm{C}(1 \mathrm{~min}), 120{ }^{\circ} \mathrm{C} / \mathrm{min}, 225^{\circ} \mathrm{C}(5.29 \mathrm{~min})$, $120^{\circ} \mathrm{C} / \mathrm{min}, 275^{\circ} \mathrm{C}(5.2 \mathrm{~min})$, and post-run $300^{\circ} \mathrm{C}(2.5 \mathrm{~min})$ resulting in a cycle time of around $20 \mathrm{~min}$. The MSD was operated in single ion monitoring (SIM) mode recording one quantifier and two qualifier masses (Table 1).

Deuterated analogs were used for every analyte, and calibration was done via standards in pure methanol. The calibration solution and the methanolic control samples were handled analogously to the eluates. Nine calibration levels were measured in duplicate. Calibrations ranged from 25 to $1,500 \mathrm{ng} / \mathrm{ml}$ (methadone), from 50 to $1,500 \mathrm{ng} / \mathrm{ml}$ (benzoylecgonine), from 5 to $150 \mathrm{ng} / \mathrm{ml}$ (codeine), from 5 to $300 \mathrm{ng} / \mathrm{ml}$ (cocaine, dihydrocodeine, morphine), and from 2.5 to $150 \mathrm{ng} / \mathrm{ml}$ (7-
Table 1 Quantifier and qualifier ions for analytes and internal standards

\footnotetext{
${ }^{a}$ Quantifier/qualifier ion used in partly automated analysis method

${ }^{\mathrm{b}}$ Quantifier/qualifier ion used in fully automated analysis method
}

\begin{tabular}{|c|c|c|c|}
\hline & Retention time on Rxi-5MS, min & Quantifier, $m / z$ & Qualifier, $m / z$ \\
\hline Cocaine & 7.38 & 182 & 303,198 \\
\hline Cocaine- $\mathrm{d}_{3}$ & 7.36 & 185 & 306,201 \\
\hline Benzoylecgonine & 7.76 & 361 & 256,346 \\
\hline Benzoylecgonine- $d_{3}$ & 7.75 & 364 & 259,349 \\
\hline Methadone & 6.57 & 223 & 294,236 \\
\hline Methadone- $\mathrm{d}_{9}$ & 6.49 & $226^{\mathrm{a}}, 303^{\mathrm{b}}$ & $303^{\mathrm{a}}, 318^{\mathrm{b}}, 242$ \\
\hline Morphine & 9.23 & 429 & 220,401 \\
\hline Morphine- $\mathrm{d}_{3}$ & 9.22 & 432 & 223,404 \\
\hline Codeine & 8.91 & 371 & 234,343 \\
\hline Codeine- $\mathrm{d}_{3}$ & 8.90 & 374 & 237,346 \\
\hline 6-Monoacetylmorphine & 9.76 & 399 & 340,400 \\
\hline 6-Monoacetylmorphine- $\mathrm{d}_{3}$ & 9.74 & 402 & 343,403 \\
\hline Dihydrocodeine & 8.49 & 373 & 315,358 \\
\hline Dihydrocodeine- $\mathrm{d}_{6}$ & 8.46 & 379 & 318,364 \\
\hline 7-Aminoflunitrazepam & 10.91 & $326^{\mathrm{b}}, 355^{\mathrm{a}}$ & $326^{\mathrm{a}}, 356^{\mathrm{a}}, 327^{\mathrm{b}}, 354^{\mathrm{b}}$ \\
\hline 7-Aminoflunitrazepam- $\mathrm{d}_{7}$ & 10.87 & 362 & 333,363 \\
\hline
\end{tabular}


Table 2 Validation data of the partly automated routine method

\begin{tabular}{|c|c|c|c|c|c|c|c|}
\hline & $\begin{array}{l}\mathrm{LOD}, \\
\mathrm{ng} / \mathrm{ml}\end{array}$ & $\begin{array}{l}\mathrm{LOQ}, \\
\mathrm{ng} / \mathrm{ml}\end{array}$ & $\begin{array}{l}\text { ULOC, } \\
\mathrm{ng} / \mathrm{ml}\end{array}$ & $\begin{array}{l}\text { Repeatability }{ }^{\mathrm{a}} \text {, } \\
\text { RSD \% }\end{array}$ & $\begin{array}{l}\text { Time-different intermediate } \\
\text { precision }^{\mathrm{a}}, \mathrm{RSD} \%\end{array}$ & $\begin{array}{l}\text { Trueness }{ }^{\mathrm{a}} \text {, } \\
\text { bias \% }\end{array}$ & $\begin{array}{l}\text { Extraction } \\
\text { efficiency }^{\mathrm{a}}, \%\end{array}$ \\
\hline Cocaine & 1.1 & 3.5 & 300 & 2.4 & 2.8 & +4.6 & 119 \\
\hline Benzoylecgonine & 9 & 47 & 1,500 & 4.1 & 5.8 & +8.9 & 29 \\
\hline Methadone & 4.2 & 16.7 & 1,500 & 3.7 & 4.6 & -1.0 & 74 \\
\hline Morphine & 1.2 & 4.9 & 300 & 6.8 & 6.8 & +13.4 & 37 \\
\hline Codeine & 0.4 & 2.6 & 150 & 6.8 & 11.3 & +2.3 & 118 \\
\hline 6-Monoacetylmorphine & 0.3 & 0.8 & 150 & 3.9 & 5.5 & +12.4 & 78 \\
\hline Dihydrocodeine & 0.8 & 4.2 & 300 & 4.1 & 5.8 & +2.8 & 61 \\
\hline 7-Aminoflunitrazepam & 0.6 & 2.5 & 150 & 7.0 & 8.6 & +5.5 & 127 \\
\hline
\end{tabular}

$L O D$ limits of detection, $L O Q$ limits of quantification, ULOC and upper limits of calibration, $R S D$ relative standard deviation

${ }^{a}$ Concentrations: $80 \mathrm{ng} / \mathrm{ml}$ for benzoylecgonine and methadone; $16 \mathrm{ng} / \mathrm{ml}$ for cocaine, morphine, and dihydrocodeine; $4 \mathrm{ng} / \mathrm{ml}$ for codeine, 6monoacetylmorphine, and 7-aminoflunitrazepam

aminoflunitrazepam, 6-monoacetylmorphine), respectively, and were calculated for $0.6 \mathrm{ml}$ serum samples. Calibration from solvent standards is often used in forensic toxicology and is accepted by the Society of Toxicological and Forensic Chemistry (GTFCh) if equivalence with matrix calibration can be proven.

In between authentic case samples, control samples like negative, low concentration, high concentration, external, and methanolic control were analyzed. According to GTFCh recommendations, a blank injection of pure derivatization solution was done after every sample, quality control, and calibration sample.

\section{Results and discussion}

Partly automated, validated routine method

The routine method was validated according to the GTFCh guidelines [30]. Validation data are presented in Table 2.
Concentrations of the analytes in the quality controls associated with the sequences were within the allowed tolerance range (according to the GTFCh recommendations of \pm 30 and $\pm 40 \%$ near the limit of quantification (LOQ), respectively) [30]. The described method is being used for routine analyses in the Institute of Legal Medicine in Duesseldorf for several years. All proficiency tests were passed successfully. The results of the analyzed routine samples were taken as reference for the automated system in order to prove its validity.

\section{Completely automated method}

The partly automated method could be successfully transferred to the completely automated system starting with the dilution of the sample (after protein precipitation) and ending with the injection into the GC/MS. Most parameters could be replicated without need for change. Some parameters were adapted for different reasons discussed in the following.

The in-syringe dilution worked properly. No carryover for any of the compounds could be detected when extracting
Fig. 4 SPE elution profile for all analytes included in this study

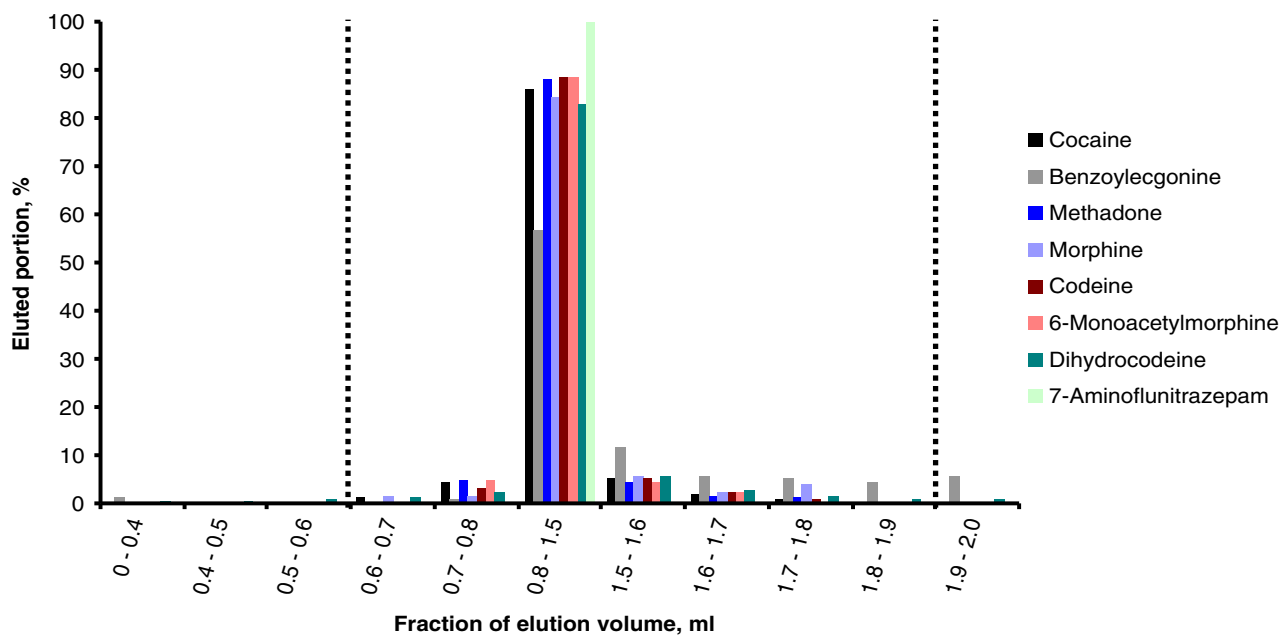


Fig. 5 Optimization of derivatization reagent composition for the completely automated method. Pure standards were derivatized with different reagents at $90{ }^{\circ} \mathrm{C}$ for $30 \mathrm{~min}$

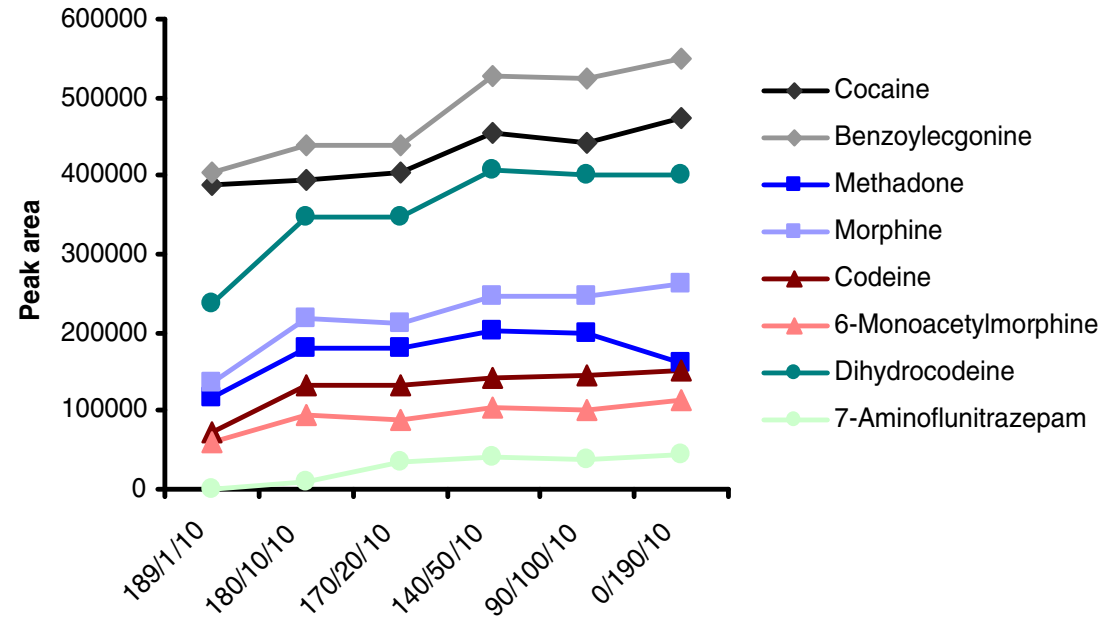

Composition isooctane/pyridine/MSTFA $(v / v / v)$ blank serum samples after analyte-positive samples. According to the elution profile (Fig. 4), the elution volume was adjusted to $1.9 \mathrm{ml}$ where the first $0.6 \mathrm{ml}$ was discarded and the following $1.3 \mathrm{ml}$ was collected in the elution vial. This volume is adequate for evaporation from a 2-ml vial in the mVAP station. Although the elution solvent consists mainly of the very volatile dichloromethane, the evaporation under controlled vacuum, heating, and shaking was very smooth and repeatable without any boiling retardation.

The derivatization procedure could be shortened from 30 to 5 min at $90{ }^{\circ} \mathrm{C}$ by using a different reagent mixture consisting of isooctane/pyridine/MSTFA 14/5/1 $(v / v / v)$ instead of isooctane/MSTFA 19/1 ( $v / v$; see Figs. 5 and 6).

For methadone and 7-aminoflunitrazepam, quantifier and qualifier masses are needed to be adapted since coelution occurred. In the case of 7-aminoflunitrazepam, probably siloxanes from vial septa also showing $\mathrm{m} / \mathrm{z} 355$ and 356 coeluted with the analyte. Choosing $\mathrm{m} / \mathrm{z} 326,327$, and 354 as quantifier/qualifiers could overcome this issue.

All in all, the semiautomated method could readily be transferred to the automated system without major optimization steps.

Almost 170 authentic serum samples and more than 50 authentic samples of other matrices (urine, different tissues, heart blood) were analyzed. All samples were processed properly by the instrument without any failure. By overlapping sample preparation steps with the GC/MS run, a throughput of around 29 samples per day could be achieved which is comparable with the partly automated method. The possible automation of the protein precipitation step was not within the
Fig. 6 Optimization of derivatization time for the completely automated method. Spiked serum samples were extracted and the eluate was derivatized with isooctane/ pyridine/MSTFA $14 / 5 / 1(v / v / v)$ at $90{ }^{\circ} \mathrm{C}$ for different times

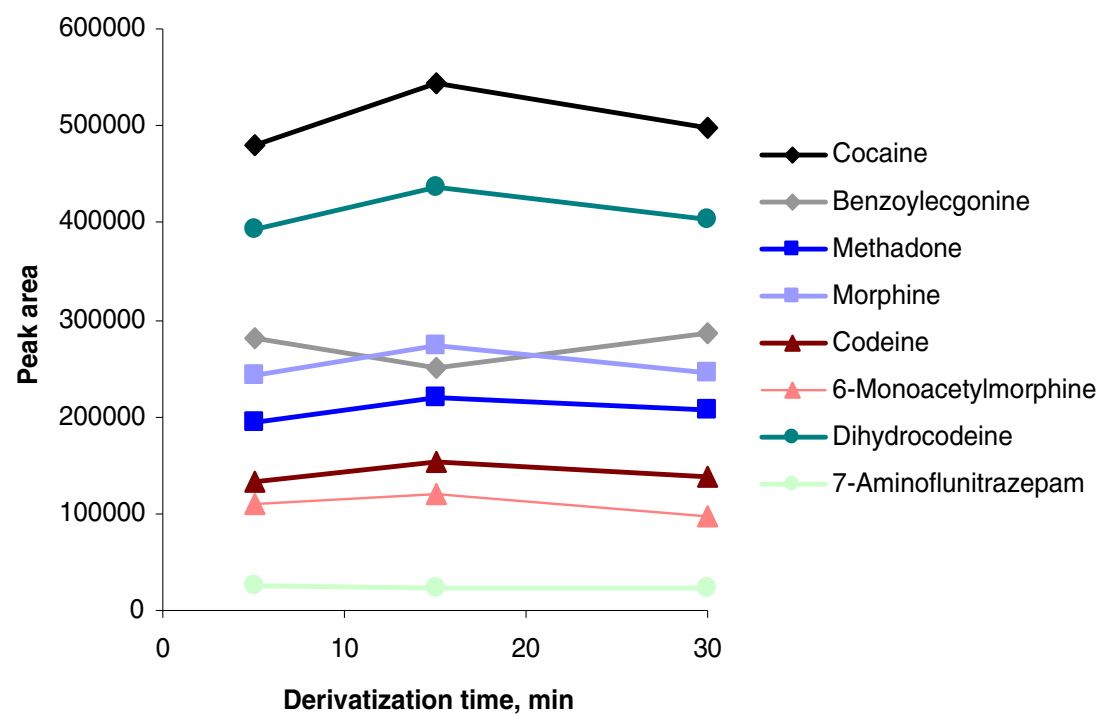


scope of the present work because of the study design (two aliquots of one sample after protein precipitation for parallel analysis). All quantification results for the control samples but one for cocaine and one for benzoylecgonine in an external control sample ( 2 and $3 \%$ below the allowed tolerance, respectively) were within the allowed tolerance ranges.

\section{Method comparison}

Results of both methods are equivalent as visible in the double logarithmic line and Bland-Altman plots (Figs. 7 and 8 and Table 3). This is true for serum samples and also for other matrix samples (urine, different tissues, heart blood). Results between the method's LOQ and the limit of detection (LOD) are included in the line plots (dashed black lines in Fig. 7) as well. Even in
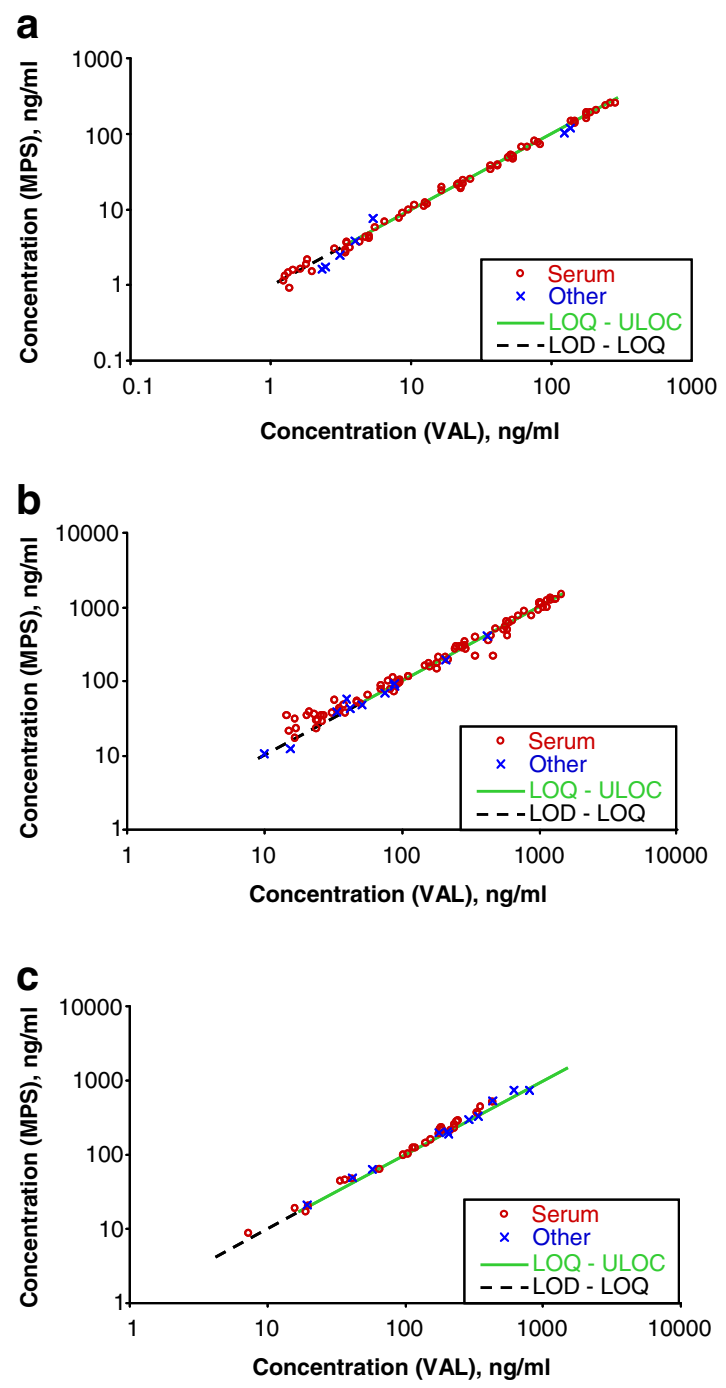

Fig. 7 Correlation of measured analyte concentrations in double logarithmic scale. Line with a slope of one (dashed black in the range from LOD to LOQ and solid green in the range from LOQ to ULOC)representing the complete equivalence of results - is shown. VAL validated partly automated method; MPS fully automated method performed on a MultiPurpose Sampler $(M P S) ; n g / m l$ nanogram per milliliter or this concentration range, the equivalence of both methods is obvious suggesting that LOQ and LOD for both methods are very similar. This indirect validation approach of comparing a large number of authentic samples reveals the accuracy and precision of the comprehensively automated method.

The analyses were run in different laboratories by different personnel at different times revealing the ruggedness of the instrumentation and both methods. Since only a couple of samples were positive for dihydrocodeine and 7 aminoflunitrazepam, these results are not plotted. Samples and quality control samples were also in good concordance for these compounds.

LOQs are in the range of other published methods, e.g., Kjaergaard Bjork et al. achieved LOQs between 2.5 and $10 \mathrm{ng} / \mathrm{mL}$ in whole blood analysis for the compounds
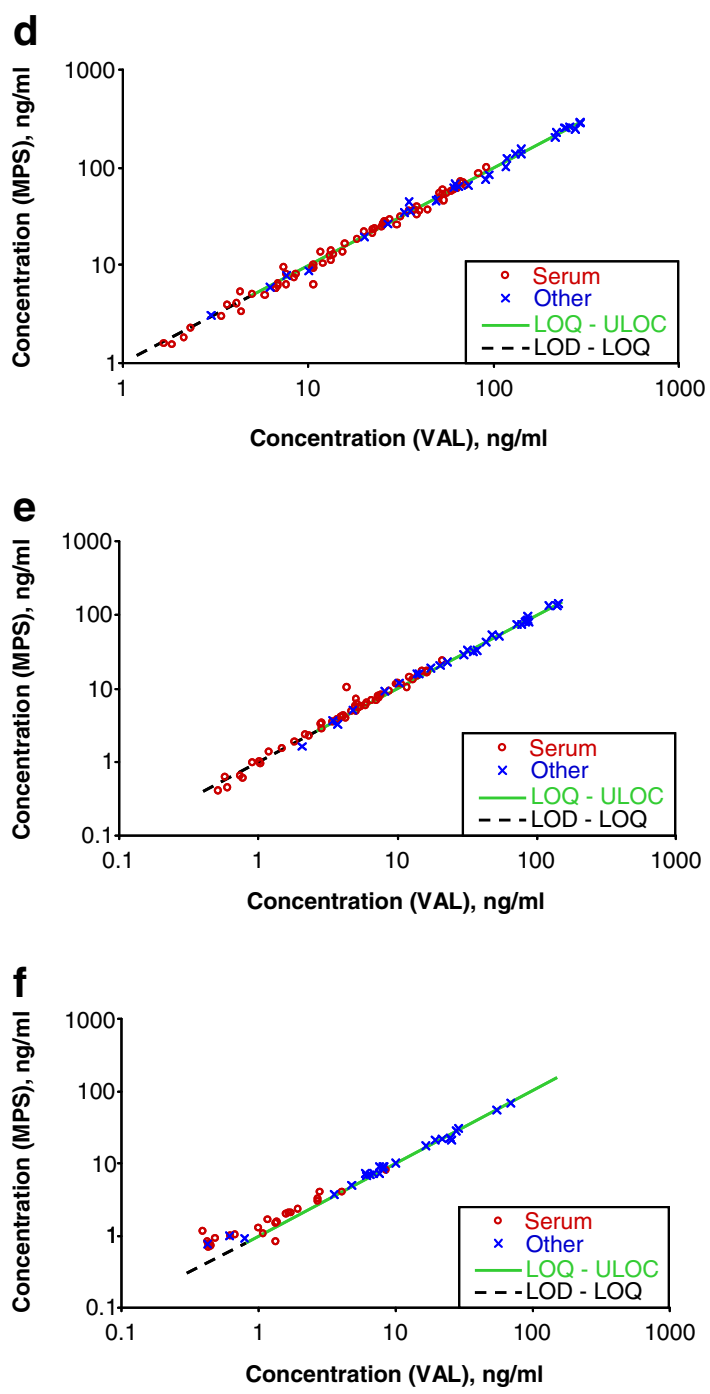

nanogram per gram if tissue is used, respectively; Other other matrices than serum - urine, blood, lyophilized kidney tissue, heart blood, lyophilized, and native brain tissue; $L O D$ limit of detection; $L O Q$ limit of quantification; $U L O C$ upper limit of calibration. a Cocaine. b Benzoylecgonine. c Methadone. d Morphine. e Codeine. f 6Monoacetylmorphine 

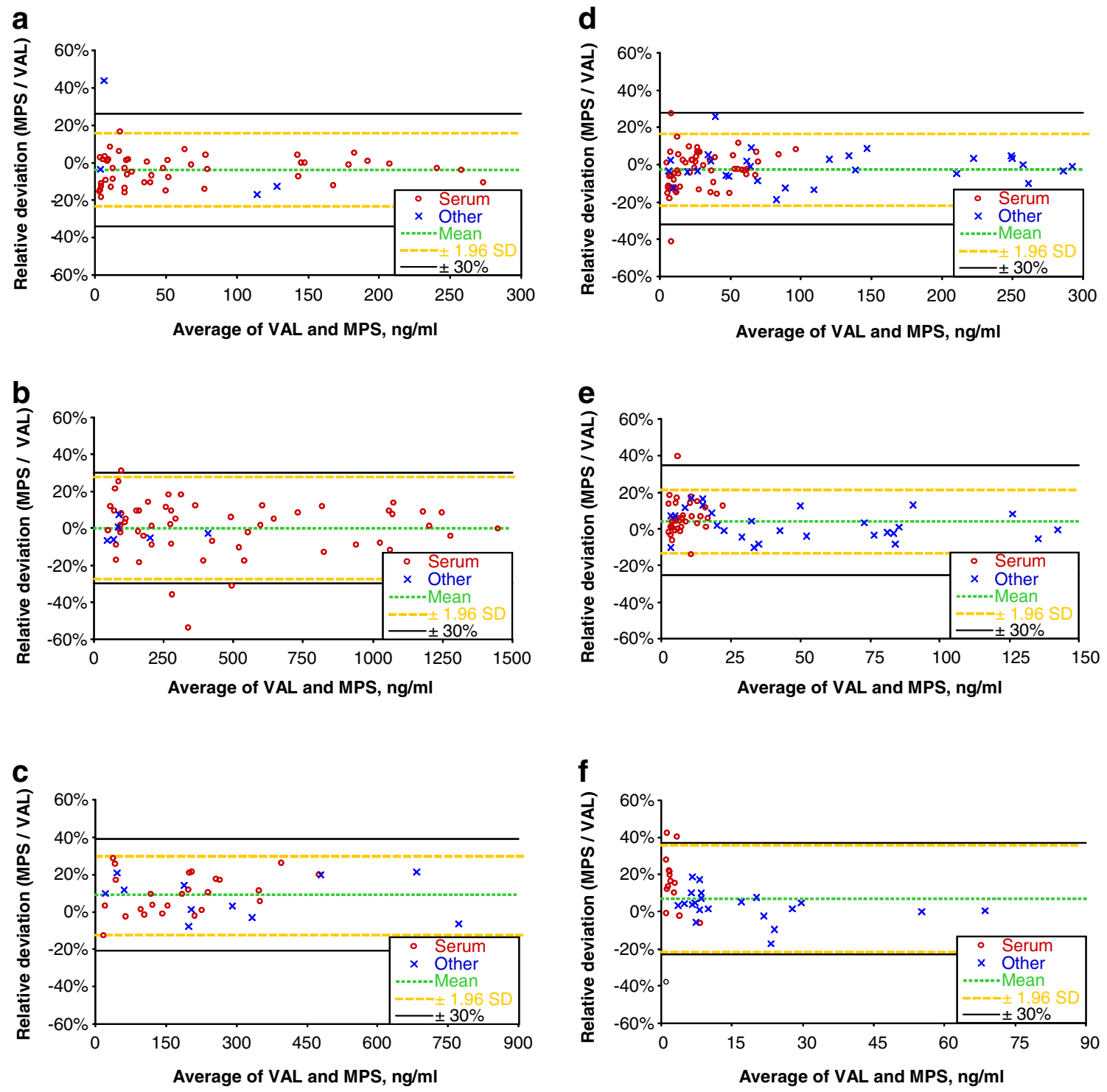

Fig. 8 Relative deviations of measured concentrations displayed as Bland-Altman plots. Only analysis values above the limit of quantification are plotted. VAL validated partly automated method; MPS fully automated method performed on a MultiPurpose Sampler (MPS); $n g / m l$ nanogram per milliliter or nanogram per gram if tissue is used,

mentioned in this work [5] and Ferreiros Bouzas et al. between 0.5 and $2.8 \mathrm{ng} / \mathrm{ml}$ from serum analyzed by LC-MS/MS [7]. According to Jones et al. [9] and Namera et al. [31], LOQs for different opiates in whole blood or serum, respectively, were $5 \mathrm{ng} / \mathrm{ml}$.

\section{Conclusions}

A unique system which mimics complex sample preparation workflows (dilution, SPE, evaporation, derivatization, injection) was employed in this study. Whereas other robotic systems enable the standalone automation of only one sample

respectively; Other: other matrices than serum—urine, blood, lyophilized kidney tissue, heart blood, lyophilized, and native brain tissue; Mean mean deviation or bias in percent; $S D$ standard deviation of percent deviations for each single sample. a Cocaine. b Benzoylecgonine. c Methadone. d Morphine. e Codeine. f 6-Monoacetylmorphine

preparation step, e.g., SPE [5, 6, 19-22] or evaporation, applications employing such comprehensive systems were rarely reported before in scientific literature. An application utilizing this specific system (autosampler plus individual modules) is even reported for the first time. In our opinion, comprehensive automation without manual intervention after putting the sample onto the autosampler offers full benefit to the user.

These are the main achievements and benefits:

- Comprehensive automation of a validated, partly automated analysis method for opioids, cocaine, and metabolites from blood serum and other matrices 
Table 3 Statistical data for the automated method in comparison to the validated method inferred from Bland-Altman plots

\begin{tabular}{lll}
\hline \multirow{2}{*}{ Analyte } & \multicolumn{2}{l}{ Statistical data from Bland-Altman plots } \\
\cline { 2 - 3 } & Bias, \% & SD, \% \\
\hline Cocaine & -3.6 & \pm 10.1 \\
Benzoylecgonine & +0.2 & \pm 14.0 \\
Methadone & +9.1 & \pm 10.7 \\
Morphine & -2.3 & \pm 9.9 \\
Codeine & +6.5 & \pm 18.0 \\
6-Monoacetylmorphine & +7.2 & \pm 14.7 \\
Dihydrocodeine $^{\mathrm{a}}$ & - & - \\
7-Aminoflunitrazepam & & - \\
\hline
\end{tabular}

Bias mean deviation between both methods in percent, $S D$ standard deviation of percent deviations for each single sample

${ }^{a}$ No Bland-Altman plot since only few positive samples were available

- Analysis results of both methods are equivalent (more than 220 authentic samples) on the basis of GTFCh recommendations

- The automated method saves manual work and reduces the risk of human errors. This makes analysis quality projectable and more independent of the users' experience

- Suitable throughput of samples adapted to the GC/MS analysis time despite the mainly serial workflow

- The automated method proved to be rugged and suitable for routine analysis in forensic laboratories

- The automated analysis system is highly flexible. Therefore, it can be employed for easy automation of other validated GC or LC analysis methods or for standalone automation of sample preparation. As proven by this work, method transfer is readily possible mainly by replicating method parameters on the automated system

Open AccessThis article is distributed under the terms of the Creative Commons Attribution License which permits any use, distribution, and reproduction in any medium, provided the original author(s) and the source are credited.

\section{References}

1. Sergi M, Bafile E, Compagnone D, Curini R, D’Ascenzo G, Romolo FS (2009) Anal Bioanal Chem 391:709-718
2. Guddat S, Solymos E, Orlovius A, Thomas A, Sigmund G, Geyer H, Thevis M, Schänzer W (2011) Drug Test Anal 3:836-850

3. Fitzgerald RL, Griffin TL, Yun Y, Godfey RA, West R, Pesce AJ, Herold DA (2012) J Anal Toxicol 36:106-111

4. Moeller MR, Kraemer T (2002) Ther Drug Monit 24:210-221

5. Kjaergaard Bjork M, Nielsen MKK, Markussen LO, Klinke HB, Linnet K (2010) Anal Bioanal Chem 396:2393-2401

6. Badawi N, Wiese Simonsen K, Steentoft A, Bernhoft IM, Linnet K (2009) Clin Chem 55:2004-2018

7. Ferreiros BN, Dresen S, Munz B, Weinmann W (2009) Anal Bioanal Chem 395:2499-2507

8. Angeli I, Minoli M, Ravelli A, Gigli F, Lodi F (2012) Forensic Sci Int 218:15-19

9. Jones AW, Holmgren A, Kugelberg FC (2008) J Anal Toxicol 32: 265-272

10. Toennes SW, Steinmeyer S, Maurer HJ, Moeller MR, Kauert GF (2005) J Anal Toxicol 29:22-27

11. Del Mar Ramirez Fernandez M, De Boeck G, Wood M, Lopez-Rivadulla M, Samyn N (2008) J Chromatogr B 875: 465-470

12. Wille SMR, Lambert WEE (2007) Anal Bioanal Chem 388:13811391

13. Maquille A, Guillarme D, Rudaz S, Veuthey J (2009) Chromatographia 70:1373-1380

14. Svanström C, Hansson GP, Svensson LD, Sennbro CJ (2012) J Pharm Biomed Anal 58:71-77

15. Gunn JA, Sweeney B, Dahn T, Bell S, Newhouse R, Terrell AR (2008) J Anal Toxicol 32:485-490

16. Snow NH (2000) J Chromatogr A 885:445-455

17. Stimpfl T, Vycudilik W (2004) Forensic Sci Int 142:115-125

18. Rossi DT, Zhang N (2000) J Chromatogr A 885:97-113

19. Jourdil N, Bessard J, Vincent F, Eysseric H, Bessard G (2003) J Chromatogr B 788:207-219

20. Lee HH, Lee JF, Lin SY, Chen PH, Chen BH (2011) J Anal Toxicol 35:162-169

21. Yawney J, Treacy S, Hindmarsh KW, Burczynski FJ (2002) J Anal Toxicol 26:325-332

22. Weinmann W, Renz M, Vogt S, Pollak S (2000) Int J Legal Med 113: 229-235

23. Chen L, Wang H, Zeng Q, Xu Y, Sun L, Xu H, Ding L (2009) J Chromatogr Sci 47:614-623

24. König S, Aebi B, Lanz S, Gasser M, Weinmann W (2011) Anal Bioanal Chem 400:9-16

25. Sturm S, Hammann F, Drewe J, Maurer HH, Scholer A (2010) J Chromatogr B 878:2726-2732

26. Del Mar Ramirez Fernandez M, Wille SMR, Samyn N, Wood M, Lopez-Rivadulla M, De Boeck G (2009) J Chromatogr B 877:21532157

27. Jagerdeo E, Montgomery MA, LeBeau MA, Sibum M (2008) J Chromatogr B 874:15-20

28. Jagerdeo E, Montgomery MA, Sibum M, Sasaki TA, LeBeau MA (2008) J Anal Toxicol 32:570-576

29. Dams R, Benijts T, Lambert WE, De Leenheer AP (2002) J Chromatogr B 773:53-61

30. Peters FT, Hartung M, Herbold M, Schmitt G, Daldrup T, Mußhoff F (2009) Toxichem Krimtech 76:185-208

31. Namera A, Nagao M, Nakamoto A, Miyazaki S, Saito T (2011) J AOAC Int 94:765-774 